\title{
JUSTINIANO Y LA REFORMA DE LOS ESTUDIOS JURÍDICOS
}

\author{
Alfonso AGUDO RUIZ \\ CATEDRÁtico DE DERECHO ROMANO \\ UNIVERSIDAD DE LA RIOJA
}

SumARIO: I. Las Instituciones de Justiniano. II. La reforma del viejo plan de estudios. III. El nuevo plan de estudios. IV. Los centros de enseñanza superior. V. La elección de los profesores. VI. Los privilegios de los profesores. VII. La Pragmatica Sanctio pro petitione Vigilii. VIII. Bibliografía. IX. Abreviaturas.

RESUMEN: A pesar del prestigio innegable que alcanzan los estudios jurídicos en las escuelas o universidades de Berito y Constantinopla, Justiniano se muestra muy crítico con dicha ordenación, que revela una nueva concepción del Derecho y, consiguientemente, de su enseñanza. Justiniano cree que la ciencia del Derecho es reconducible a un sistema acabado del que es posible ofrecer a los estudiantes una exposición completa y cerrada. El nuevo plan de estudios que Justiniano diseña y establece en la Constitución Omnem tiene una duración de cinco años y un preciso material de estudio, que naturalmente es su reciente Compilación. Es un plan sistemático, gradual, completo, armónico, de contenido inicialmente más conceptual -como corresponde a los estudiantes que se inician en el Derecho- y luego, sobre todo al final, esencialmente práctico. Un plan perfectamente programado en cuanto a su contenido. Y explícitamente reglamentado en cuanto al material y método de trabajo: las obras de la compilación -Instituciones, Digesto y Código- que hay que comprender y, en cierto modo, aprender.

Palabras Clave: Justiniano, Instituta, Omnem, Pragmatica Sanctio.

ABSTRACT : Althougt the undeniable prestigious of the juridical studies in the Schools or Universities of Berito and Constantinople, Justinian is very critical with this regulation, which implies a new concept of the Laws and consequently of his teaching. Justinian thinks that the Law sciences can renew to a finished system, of which it is possible to offer a complete and closed exposition to the students. The new course of studies, which Justinian designs and establishes in the Constitution Omnem is five years long and has specific teaching material, which is of course his new Compilation. It is a systematic, gradual, complete and harmonic plan, whose contents are more conceptual at the beginning -such as it concerns to the students who learn Laws- and then, especially at the end, essentially practical. It is a perfectly programmed plan with regard to its contents and explicitly regulated with regard to the material and studies method: the works of the Compilation -Institutions, Digest and Code- that one must understand and learn in certain way.

KEYWORDS: Justiniano, Instituta, Omnem, Pragmatica Sanctio. 


\section{Las Instituciones de Justiniano}

La existencia del Codex Iustinianus ${ }^{\mathrm{T}}$ y la ya pronta publicación de la compilación de las obras de la jurisprudencia, digesta o pandectae ${ }^{2}$ hacían necesaria una reforma del plan de estudios de Derecho para adaptarlo a los profundos cambios que se habían producido en las estructuras del derecho positivo. En efecto, como afirma Cannata, «Justiniano, o quizá más precisamente Triboniano y sus colaboradores, comprendieron que lo que la historia llamaría el Corpus Iuris Civilis no era una simple compilación, sino una profunda reforma del derecho. Habían operado una síntesis de la tradición clásica, de la legislación postclásica, de la práctica y de las concepciones de las escuelas de Oriente, y esta síntesis formaba una trama completamente nueva a la que el derecho positivo se encontraba anudado de ahora en adelante. Además, el nuevo soporte no podía darse a conocer con la colección de las constituciones ni con la de las obras de los juristas; evidentemente tampoco estaba presente en las antiguas síntesis institucionales. Desde que Justiniano y sus colaboradores se dieron cuenta de esa laguna, se dispusieron a cubrirla mediante la

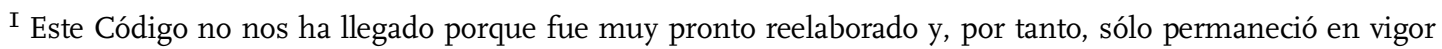
cinco años (7 de abril del 529-534). Fue compuesto en un único año: ordenado por la constitución Haec quae necessario del I3 de enero del año 528 y promulgado el 7 de abril del año 529 por la constitución Summa rei publicae. Esta última ley (3 y 4) derogaba los Códigos Gregoriano, Hermogeniano y Teodosiano así como las Novelas imperiales promulgadas tras él; entre las antiguas fuentes, sólo las obras de los juristas conservaban su valor, que debían ser utilizadas según las reglas de la Ley de Citas.

La comisión encargada de redactar el Codex Iustinianus había sido nombrada por la Const. Haec quae necessario (I). Estaba formada por un ministro (Juan de Capadocia, presidente), seis funcionarios (Leoncio, Focas, Basilides, Tomás, Triboniano y Constantino), dos abogados de los Tribunales de la capital (Dióscoro y Presentino) y un profesor de la Universidad de Constantinopla y ministro (Teófilo). Obsérvese que el elenco de comisionados muestra claramente que Justiniano al inicio de su reinado confía sólo en funcionarios para realizar su proyecto de reordenación legislativo y judicial, dejando a un lado a los profesores de Derecho. Teófilo es elegido más por su cargo de comes sacri consistorii que por su grado académico.

Esta situación aparece anteriormente. Recordemos a los comisionados por Teodosio II para realizar sus proyectos codificadores. C. Th. I,I,5, del 26 de marzo del 429 indica las siguientes personas: Antiochus vir inlustris, exquaestor et praefectus, Antiochus vir inlustris, quaestor sacri palatii, Theodorus vir spectabilis, comes et magister memoriae, Eudicius et Eusebius, viri spectabiles magistri scriniorum, Iohannes vir spectabilis ex comes sacrarii, Comarzo et Eubulus viri spectabiles ex magistri scriniorum, Apelles vir disertissimus scholasticus . Como se ve, una comisión compuesta por funcionarios y ex funcionarios, sin que ningún docente forme parte. La comisión mencionada en C. Th. I,I, 6,2, del 20 de diciembre del 435 indica: Antiochus, amplissimus atque gloriosissimus praefectorius ac consularis, Eubulus, inlustris ac magnificus comes et quaestor noster, Maximinus vir inlustris quaestoriae dignitatis ornatus, Sperantius, Martyrius, Alypius, Sebastianus, Apollodorus, Theodorus, Eron spectabiles comites consistoriani, Maximinus, Epigenes, Diodorus, Procopius, spectabiles comites et magistri sacrorum scriniorum, Erotius vir spectabilis ex vicariis iuris doctor, Neoterius vir spectabilis ex.... También esta comisión esta compuesta solamente por funcionarios, entre los que figura un iuris doctor .
}

${ }^{2}$ Esta compilación del ius llevó la denominación oficial de digesta o pandectae (Deo auctore, I2; Tanta, I). Fue compuesta en tan sólo tres años: ordenado por la Constitución Deo auctore del I5 de diciembre del año 530 y promulgada el i 6 de diciembre del año 533 por la Constitución Tanta. Justiniano la definió como una empresa tan nueva y tan difícil que debería haber sido considerada como irrealizable (Deo auctore, 2). En efecto, no se trataba sólo de distribuir entre los comisionados la lectura de los libros de los juristas que habían contado con el ius respondendi, de elegir los textos y de proceder a su reelaboración en los títulos que formarían los 50 libros previstos siguiendo el orden del edicto del pretor (Deo auctore, 5). Por cierto que los compiladores utilizaron también las obras de los juristas de época republicana, así como Labeón, Pomponio y Gayo, y también algunos escritos de juristas tardíos como Hermogeniano y Arcadio Carisio. Además, según las órdenes de Justiniano había que eliminar las contradicciones y las repeticiones (Deo auctore , 4), modificar los textos para esclarecerlos y adaptarlos al derecho vigente (Deo auctore, $7 ;$ io) y armonizar el contenido del Digesto con el del Código (Deo auctore , 8; 9).

La capacidad demostrada por Triboniano en la elaboración del Codex Iustinianus, hizo que Justiniano confiara en él hasta el punto de que la Constitución de la concepción del Digesto está dirigida a Triboniano y no contiene el nombramiento de una comisión, aspecto éste dejado a su criterio (Deo auctore, 3). Resultó de ello una comisión muy distinta de la anterior, en la que Triboniano equilibró los conocimientos teóricos aportados por los profesores con los conocimientos prácticos aportados por los abogados (Tanta , 9). Estaba formada por un ministro especialmente encargado de la actividad normativa imperial (Triboniano, presidente), dos profesores de la Universidad de Constantinopla (Teófilo y Cratino), dos profesores de la Escuela de Berito (Doroteo y Anatolio), un funcionario-ministro (Constantino) y once abogados (Menna, Constantino, Juan, Esteban, Prosdocio, Eutolmio, Timoteo, Leónidas, Leoncio, Platón y Jacobo). 
redacción de un nuevo manual de Institutiones y mediante la reforma de los estudios jurídicos» (I996, I25).

La primera medida adoptada por Justiniano, en fecha incierta del año 533, fue encargar de manera informal ${ }^{3}$ a una comisión restringida la redacción de un manual institucional ${ }^{4}$. El encargo fue cumplido con gran rapidez por Triboniano, Teófilo y Doroteo 5 incluso antes de la promulgación del Digesto; en efecto, la obra fue aprobada por la Constitutio Imperatoriam del 2I de noviembre del año 533. Las Instituciones de Gayo así como las demás obras institucionales tardo-clásicas -de Paulo, Ulpiano, Marciano y Florentino-, completadas con textos procedentes de las res cottidianae, algunos pasajes del Digesto -en ese momento prácticamente concluido- y algunas constituciones imperiales, formaban la base de estas Instituciones ${ }^{6}$. Los cuatro libros de las Institutiones aparecen divididos en títulos, cada uno de éstos con una rúbrica indicadora del contenido. A diferencia del Código y del Digesto, donde se señala expresamente la procedencia de cada texto $^{7}$, en las Instituciones el discurso se presenta en forma de texto corrido, sin desvelar las fuentes de donde proceden los fragmentos, escrita en primera persona, como si el propio Emperador hablara a los estudiantes.

Debe destacarse que esta obra, aunque destinada a la enseñanza, fue promulgada como ley ${ }^{8}$. En opinión de Bonini, «se puede observar que la obra representa, justo por sus finalidades didácticas, no sólo el momento de mayor síntesis, sino también el de más sosegada reflexión en todo el ciclo de las compilaciones justinianeas. Se trata, pues, de una obra en la que, a través de la neta separación de las partes históricas y de las perspectivas, se transparentan con particular evidencia las verdaderas intenciones normativas del emperador, lo que permite también dar cuenta, de algún modo, de novedades 'inexpresables' con los materiales recogidos en el Digesto (e incluso, a veces, con los recogidos en el Código)» (I979, 66 y ss.).

En cuanto al orden de materias, el primer libro trata de la temática de personas. El segundo libro, de las cosas, la propiedad y los demás derechos reales y los testamentos. El tercer libro, de la sucesión intestada, de las obligaciones derivadas de contrato y de las

\footnotetext{
${ }^{3}$ A diferencia de lo acostumbrado, nos ha llegado sólo la Constitución con la cual fue publicada la obra: Const. Imperatoriam del 2I de noviembre del año 533. Esta expresión la utilizan, entre otros, BONINI ( I979, 6I).

${ }^{4}$ Sobre las diversas motivaciones que indujeron a Justiniano a elaborar sus Institutiones , vid. ARCHI ( I978, IOI y ss.). Un curioso estudio que relaciona las distintas partes del Corpus iuris civilis con el calendario romano, corresponde a SINAÏSKI ( I935, I80 y ss.).

5 Const. Imperatoriam, 3; Tanta, II. DE FRANCISCI, afirma que «según una conjetura probable de Huschke, Triboniano se debió reservar la presidencia, y los otros dos harían la compilación de dos libros cada uno. Esta hipótesis se funda en diversos detalles. Ante todo, las referencias que se hacen a otros pasajes de las mismas Institutiones, cuando figuran en los dos primeros libros no van más allá de esos dos primeros libros, y las que figuran en los dos segundos también se limitan a esos dos últimos; en los dos últimos libros se exponen argumentos ya expuestos en los dos primeros, sin recordarse la exposición precedente; hay una notable diferencia de estilo entre los dos primeros y los dos últimos; el compilador de los dos primeros utilizó las Institutiones de Ulpiano, y el de los dos últimos las Institutiones de Paulo; el primero parece que tenía conocimiento de exposiciones hechas al emperador sobre proyectos de leyes, y que en cambio no tenía el segundo. Estas diferencias han hecho que Huschke atribuya los dos primeros libros a Doroteo, y los dos últimos a Teófilo; mientras que Ferrini hace la atribución contraria» (I954, 7I5).

${ }^{6}$ Sobre las fuentes de las Institutiones de Justiniano, vid. AMELOTTI (I983, 75 y ss.); BONINI (I979, 6ry ss. ). Un intento notable de reunir los libros de Instituciones es el de NARD (I973, 3 vols.).

${ }^{7}$ En el Código, cada constitución comienza con el nombre de los emperadores y la indicación del destinatario y concluye con la fecha de emisión. En el Digesto, cada texto viene precedido por la indicación de su autor, la obra y el libro de procedencia.

${ }^{8}$ Imperatoriam , 6; Tanta, II. ARCHI, afirma que «este doble carácter responde a la finalidad política de consolidar el imperium Romanum, para lo cual era imprescindible la creación de un eficaz sistema jurídico donde el conocimiento del Derecho resultase fácil, accesible» (I995, 74 y ss.).
} 
obligaciones en general. El cuarto libro, de las obligaciones derivadas de delito, de los procesos privados y de los procesos públicos?

En Justiniano vemos reflejado su deseo no sólo de aclarar -depurando y ordenando todo el derecho vigente, en los libros del Código y del Digesto-, sino de facilitar el estudio del Derecho. Después de un parágrafo preliminar, dedicado al habitual binomio «arma et leges», como fundamento de la «imperatoria maiestatis» ${ }^{\mathrm{IO}}$, y de dos parágrafos (I y 2) ${ }^{\text {II }}$ dedicados al recuerdo de las más recientes empresas bélicas y jurídicas, Justiniano expresa en la Constitución Imperatoriam $(3)^{12}$ su preocupación pedagógica, no quiere que la juventud estudiosa tenga que acudir a las obras antiguas, trata de evitar el estudio superfluo y lograr rápidamente la capacitación de los que se sienten llamados a los estudios jurídicos. $\mathrm{Su}$ propósito es ofrecer a los jóvenes un instrumento para aprender los «primas legum cunabula»; estos primeros elementos deberán ser extraídos no ya «ab antiquis fabulis», sino «ab imperiali esplendore», evitando las cosas inútiles y erróneas, y sobre todo comenzando a leerse desde el primer año de curso y no sólo «post quadriennium» las constituciones imperiales (sólo las plasmadas en el manual institucional se entiende): el estudio de las normas imperiales se convertirá así en «et initium ... et finis legum eruditionis». Más tarde $(4)^{13}$, declara el carácter propedéutico de las Institutiones «totius legitimae scientiae prima

\footnotetext{
9 FERNÁNDEZ DE BUJÁN, A. (Madrid 20I0, 2I6).

Io Imperatoriam, pr.: Imperatoriam maiestatem non solum armis decoratam, sed etiam legibus oportet esse armatam, ut utrumque tempus, et bellorum et pacis, recte possit gubernari, et princeps Romanus victor existens non solum in hostilibus proeliis, sed etiam per legitimos tramites calumniantium iniquitates expellat, et fiat tam iuris religiosissimus, quam victis hostibus triumphator .
}

Algunas constituciones imperiales realzan de modo curioso la alta importancia de la abogacía y su equiparación a la defensa de la patria con las armas. Nos lo testifica una constitución promulgada en el año 469 por León I y Antemio, que describe el elogio más significativo de la abogacía: C. J. 2.7.I4 (Impp. Leo et Anthemius AA. Callicrati P.P. Illyrici): Advocati, qui dirimunt ambigua fata causarum suaeque defensionis viribus in rebus saepe publicis ac privatis lapsa erigunt, fatigata reparant, non minus provident humano generi, quam si praeliis atque vulneribus patriam parentesque salvarent. Nec enim solos nostro Imperio militare credimus illos, qui gladiis clypeis et thoracibus nituntur, sed etiam advocatos; militant namque causarum patroni, qui gloriosae vocis confisi munimine laborantium spem vitam et posteros defendunt.

La mencionada constitución recuerda el parangón que hace Tácito, Dial. orat. 5, entre la lucha forense y la bélica: Nam si ad utilitatem vitae omnia factaque nostra dirigenda sunt, quid est utilius quam eam exercere artem, qua semper armatus praesidium amicis, opem alienis, salutem periclitantibus, invidis vero et inimicis metum et terrorem ultro feras, ipse securus et quadam velut perpetua potentia et potestate munitus? Cuius vis et utilitas rebus prospere fluentibus aliorum perfugio et tutela intellegitur: sin proprium periculum increpuit, non hercule lorica et gladius in acie firmius munimentum quam reo et periclitanti eloquentia praesodium simul ac telum, quo propugnare pariter et incessere sive in iudicio, sive in senatu, sive apud principem possis .

Sobre el binomio «arma et iura» en el lenguaje legislativo justinianeo, vid. DANNENBRING (I972, II3 y ss.); HERNÁNDEZ TEJERO (I972, 229 y ss.); ARCHI (I978, IOI y ss.); BONINI, (I979, 95 y ss.).

II Imperatoriam, I: Quorum utramque viam cum summis vigiliis summaque providentia, annuente Deo, perfecimus. Et bellicos quidem sudores nostros barbaricae gentes sub iuga nostra deductae cognoscunt; et tam Africa, quam aliae innumerosae provinciae post tanta temporum spatia nostris victoriis, a coelesti numine praestitis, iterum ditioni Romanae nostroque additae imperio protestantur. Omnes vero populi legibus tam a nobis promulgatis quam compositis reguntur. 2: Et cum sacratissimas constitutiones antea confusas in luculentam ereximus consonantiam, tunc nostram extendimus curam ad immensa veteris prudentiae volumina, et opus desperatum, quasi per medium profundum euntes, coelesti favore iam adimplevimus .

${ }^{12}$ Imperatoriam, 3: Cumque hoc Deo propitio peractum est, Triboniano, viro magnifico, magistro et exquaestore sacri palatii nostri, nec non Theophilo et Dorotheo, viris illustribus, antecessoribus (quorum omnium solertiam et legum scientiam et circa nostras iussiones fidem iam ex multis rerum argumentis accepimus) convocatis, specialiter mandavimus, ut nostra auctoritate nostrisque suasionibus componant Institutiones; ut liceat vobis prima legum cunabula, non ab antiquis fabulis discere, sed ab imperiali splendore appetere, et tam aures quam animae vestrae nihil inutile nihilque perperam positum, sed quod in ipsis rerum obtinet argumentis, accipiant; et quod priore tempore vix post quadriennium prioribus contingebat, ut tunc constitutiones imperatorias legerent, hoc vos a primordio ingrediamini, digni tanto honore tantaque reperti felicitate, ut et initium vobis et finis legum eruditionis a voce principali procedat.

${ }^{13}$ Imperatoriam, 4: Igitur post libros quinquaginta Digestorum seu Pandectarum, in quibus omne ius antiquum collatum est, quos per eundem virum excelsum Tribonianum nec non ceteros viros illustres et facundissimos confecimus, in hos quattuor libros easdem Institutiones partiri iussimus, ut sint totius legitimae scientiae prima elementa . 
elementa», y aclara $(5)^{14}$ que la obra se expone con brevedad «breviter». Los redactores de las Institutiones vuelven a insistir en la necesidad de iniciar de una manera breve y sencilla a los estudiosos en el aprendizaje del Derecho (I. J. I.I.2): «...ita videntur posse tradi commodissime, si primo levi ac simplici via, post deinde diligentissima atque exactissima interpretatione singula tradantur». Allí Justiniano dirá que se facilita enormemente la enseñanza si se comienza con un método fácil y simple, hasta abocar a un estudio más profundo y exacto de cada tema, porque si desde el principio recargamos con multitud y variedad de materias la inteligencia todavía no formada de los jóvenes estudiantes, una de dos: o les obligamos a abandonar el estudio o les llevaremos, con un extraordinario esfuerzo, que con frecuencia les desalienta, a donde también habrían llegado, plenamente maduros, sin fatigarse demasiado y sin perder la confianza en sí mismos, en caso de haberse utilizado un sistema de enseñanza más llevadero. La Const. Imperatoriam $(7)^{15} \mathrm{se}$ cierra con la recomendación de Justiniano a los estudiantes para que se apliquen en los estudios jurídicos y puedan así el día de mañana ser excelentes funcionarios o eximios abogados.

Como afirma Hernández Tejero, «Justiniano ofrece a los juristas lo más que podía ofrecer quien dedicaba su vida a la empresa de reconstruir la grandeza del Imperio romano. Les ofrece ese Imperio reconstruido. Frente a tanta grandeza poco importan la sacralización de las instituciones políticas, propias de la terminología bizantina, que se advierten en la Constitución, y las pretensiones inmovilistas de un emperador que quería morir asido a una ilusión imperecedera» (I972, 234).

\section{La reforma del viejo plan de estudios}

Unos días después de la publicación de las Instituciones y en la misma fecha de la Constitución Tanta que promulgó el Digesto, Justiniano reforma el viejo plan de estudios universitario para adaptarlo a la nueva compilación a través de la Constitución Omnem del I6 de diciembre del año 533, dirigida a los ocho profesores más prestigiosos de la época de las Universidades de Berito y Constantinopla, al frente de los cuales figuran Teófilo -que moriría en Constantinopla en el 536- y Doroteo -profesor en la Escuela de Berito-; junto a éstos son mencionados Teodoro, Isidoro, Anatolio, Taleleo, Cratino y Salamino ${ }^{\mathrm{I}}$.

\section{Así comienza la Constitución Omnem :}

Omnem rei publicae nostrae sanctionem iam esse purgatam et compositam tam in quatuor libris Institutionum seu elementorum, quam in quinquaginta Digestorum seu Pandectarum, nec non in duodecim Imperialium Constitutionum, quis amplius quam vos cognoscit?

Esta declaración con la que Justiniano abre la Constitución Omnem revela una nueva concepción del Derecho y, consiguientemente, de su enseñanza, que para ser comprendida en sus justos términos debe enmarcarse dentro de una amplia reforma constitucional de la cultura y de la organización jurídica del Estado romano que de ahora en adelante se llamará bizantino. Justiniano cree que la ciencia del Derecho es reconducible a

${ }^{14}$ Imperatoriam, 5: In quibus breviter expositum est, et quod antea obtinebat, et quod postea desuetudine inumbratum ab imperiali remedio illuminatum est.

${ }^{15}$ Imperatoriam, 7: Summa itaque ope et alacri studio has leges nostras accipite, et vosmetipsos sic eruditos ostendite, ut spes vos pulcherrima foveat, toto legitimo opere perfecto, posse etiam nostram rempublicam in partibus eius vobis credendis gubernare.

${ }^{16}$ Cfr. BONINI, afirma que «parecen haber sido sólo dos, a los cuales se añadían un cierto número de profesores privados» (I979, 68). Sobre la actividad escolar y científica de los citados ocho profesores, vid. COLLINET ( I925, I86 y ss.); AMELOTTI, (I983, III y ss.). 
un sistema acabado del que es posible ofrecer a los estudiantes una exposición completa y acabada.

No faltan ejemplos de esta nueva concepción del Derecho en la Constitución sobre la reforma de los estudios jurídicos. En el párrafo 3 de la Const. Omnem , a propósito del programa de los estudiantes de segundo año, afirma: «... sed eosdem libros de iudiciis vel de rebus totos et per suam consequentiam accipiebant, nullo penitus ex his derelicto...». Como opina Archi, «es evidente que esta exigencia de la totalidad de la lectura, lejos de ser una pedantería imperial, corresponde a una concepción de fondo presente en todos los años de la carrera de Derecho» (I978, I06). Esta concepción de fondo se aprecia claramente en el párrafo 5 de la citada Constitución:

... nihil iis legitimae scientiae decerit, sed omnem ab initio usque ad finem suis animis amplectantur, et quod paene in alia nulla evenit arte, cum etsi vilissimae sint, omnes tamen infinitae sunt haec sola scientia habeat finem mirabilem, in praesenti tempore a nobis sortita .

En efecto, para Archi «en la concepción justinianea el derecho es una scientia, una legitima scientia, cuyo aprendizaje debe producirse siguiendo una exposición orgánica y racional y no desarticulada, fragmentaria y memorística. Puntualiza el mencionado autor la diferente concepción de la legitima scientia para los clásicos y para Justiniano. Para los primeros, el derecho clásico es ante todo derecho jurisprudencial y, consiguientemente, los propios juristas tienen conjuntamente la función creadora y docente. Para Justiniano, por el contrario, la scientia iuris es algo externo a los juristas; éstos la deben conocer, pero no es objeto de una actividad creadora en el sentido de los antiguos jurisconsultos, deben limitarse a enseñarla» (1978, ıо6 y ss.).

Para Fernández Barreiro, «tal ideología era, después de todo, congruente con una política del derecho que partía del presupuesto del monopolio de la potestad imperial en cuanto a la determinación del contenido del ordenamiento jurídico, reservándose aquélla también la facultad de su interpretación» $(1998,54)$.

No debe sorprender, desde esta nueva concepción de la scientia iuris, que la enseñanza resulte claramente intervenida por la voluntad del Emperador: los profesores deben limitarse a conocerla y enseñarla, pero no a estudiarla creativamente, a la manera de los juristas clásicos, y esto ha de ser observado no sólo por vosotros, sino por aquellos que os sigan en el ínclito camino de la instrucción en el Derecho (Omnem, pr.):

... sed cum vos et omnes postea professores legitimae scientiae constitutos etiam hoc oportuerat sciri, quae et in quibus temporibus tradi necessarium studiosis credimus, ut ex hoc optimi atque eruditissimi efficiantur: ideo praesentem divinam orationem ad vos praecipue faciendam existimamus, quatenus tam prudentia vestra quam ceteri antecessores, qui eandem artem in omne aevum exercere maluerint, nostris regulis observatis inclytam viam eruditionis legitimae possint ambulare .

Sobre estas bases, el método de enseñanza habría consistido, para la mayor parte de profesores, en traducir, resumir los fragmentos del Digesto, y añadir solamente algunas referencias.

En esta línea de intervencionismo, Justiniano traza la actuación de los profesores indicándoles, por una parte, que las Instituciones deben ser explicadas en primer lugar, y por otra, que de los cincuenta libros que componen el Digesto basta tan sólo la explicación de treinta y seis de éstos (Omnem, pr. in fine):

... Itaque dubio procul quidem est, necesse esse Institutiones in omnibus studiis primum sibi vindicare locum, utpote prima vestigia cuiusque scientiae mediocriter tradentes; ex libris autem quinquaginta nostrorum Digestorum sex et triginta tantummodo sufficere tam ad vestram expositionem, quam ad iuventutis eruditionem iudicamus . 
Como observa Archi, «concebidos los Digesta como una collatio de todo el ius antiquum, en los arcana penetralia en los que los homines rudes no están en disposición de introducirse, las Institutiones tienen la función de dar a los estudiantes los totius legitimae scientiae prima elementa. Por tanto, desde el punto de vista didáctico, la secuencia establecida por Justiniano es lógica, las Institutiones tienen un carácter propedéutico a los Digesta» (1978, I04).

En opinión de Volterra, «con estas medidas Justiniano intenta suprimir para siempre toda la actividad creadora y personal de los juristas y de la escuela, reduciendo su función a la enseñanza mecánica de su compilación en los límites y con los métodos rigurosamente prescritos. Esto significa por parte de Justiniano el desconocimiento más absoluto de aquello que había sido la característica del Derecho romano y de su desarrollo histórico» (1967, 99).

A pesar del prestigio innegable que alcanzan los estudios jurídicos en las escuelas de Berito y Constantinopla, Justiniano se muestra muy crítico con dicha ordenación de los estudios y subraya las graves lagunas y las incongruencias de tal regulación que quedaban reducidas a papel mojado muchas veces por la imposibilidad de desarrollar los programas adecuadamente $^{\mathrm{r} 7}$. Veamos su valoración (Omnem, I):

Et antea quidem, quemadmodum et vestra scit prudentia, ex tanta legum multitudine, quae in librorum quidem duo milia, versuum autem tricies centena extendebatur, nihil aliud nisi sex tantummodo libros et ipsos confusos et iura utilia in se perraro habentes a voce magistra studiosi accipiebant, ceteris iam desuetis, iam omnibus inviis. In his autem sex libris Gaii nostri Institutiones et libri singulares quattuor, primus de illa vetere re uxoria, secundus de tutelis et tertius nec non quartus de testamentis et legatis connumerabantur: quos nec totos per consequentias accipiebant, sed multas partes eorum quasi supervacuas praeteribant. Et primi anni hoc opus legentibus tradebatur non secundum Edicti perpetui ordinationem, sed passim et quasi per saturam collectum et utile cum inutilibus mixtum, maxima parte inutilibus deputata. In secundo autem anno praepostera ordinatione habita prima pars legum iis tradebatur, quibusdam certis titulis ab ea exceptis: cum erat enorme post Institutiones aliud legere, quam quod in legibus et primum positum est et istam nuncupationem meruerit. Post eorum vero lectionem neque illam continuam, sed particularem et ex magna parte inutilem constitutam tituli alii eis tradebantur tam ex illa parte legum, quae de iudiciis nuncupatur et ipsis non continuam, sed raram utilium recitationem praebentibus, quasi cetero toto volumine inutili constituto quam ex illa quae de rebus appellatur, septem libris semotis et in his multis partibus legentibus inviis, utpote non idoneis neque aptissimis ad eruditionem constitutis. In tertio autem anno quod ex utroque volumine, id est de rebus vel de iudiciis, in secundo anno non erat traditum, accipiebant secundum vicissitudinem utriusque voluminis: et ad sublimissimum Papinianum eiusque responsa iter eis aperiebatur: et ex praedicta responsorum consummatione, quae decimo et nono libro concludebatur, octo tantummodo libros accipiebant, nec eorum totum corpus eis tradebatur, sed pauca ex multis et brevissima ex amplissimis, ut adhuc sitientes ab iis recederent. His igitur solis a professoribus traditis Pauliana responsa per semet ipsos recitabant, neque haec in solidum, sed per inperfectum et iam quodammodo male consuetum inconsequentiae cursum. Et hinc erat in quartum annum omnis antiquae prudentiae finis ...

Justiniano comienza resaltando que anteriormente, de toda la multitud de leyes que llenaban hasta dos mil libros, y hasta tres millones de líneas, los estudiantes oían a sus maestros tan sólo seis libros, poco claros y que raras veces contenían derecho de utilidad, y los otros, o habían caído en desuso o eran inaccesibles para todos.

Como afirma Archi, «Justiniano condena el hecho de que los iura se estudiasen en un número tan limitado con relación a la riqueza de la tradición clásica». Esta crítica se concreta en dos aspectos negativos, por una parte, el exiguo número de obras seleccionadas

\footnotetext{
${ }^{17}$ BONINI , (I979, 68).
} 
de la antigua jurisprudencia romana y, por otra, el malacostumbrado método de saltar por partes. Esta última consideración justifica la segunda crítica de Justiniano a los métodos del pasado. Se deplora que la lectura del texto no la realice el maestro de manera continua. Lo dice para los alumnos del primer año «... nec totos per consequentias accipiebant, sed multas partes eorum quasi supervacuas praeteribant». Lo repite para los de segundo año «...eque illam continuam, sed particularem... et ipsis non continuam... recitationem praebentibus». Lo mismo dice para los de tercer año «... nec eorum totum corpus iis tradebatur, sed pauca ex multis, et brevissima ex ampplissimis, ut adhuc sitientes ab iis recederent». Y lo vuelve a repetir para los de cuarto año «per semet ipsos recitabant, neque haec in solidum, sed per imperfectum et iam quodammodo male consuetum inconsequentiae cursum» (1978, 105).

Justiniano tiene un juicio muy negativo sobre el antiguo plan de estudios de Derecho de Berito y Constantinopla. Su valoración se resume en este párrafo (Omnem, i in fine):

...si quis ea, quae recitabant, enumerare mallet, computatione habita inveniret, ex tam immensa legum multitudine vix versuum sexaginta millia eos suae notionis perlegere, omnibus aliis deviis et incognitis constitutis, et tunc tantummodo ex aliqua minima parte recitandis, quoties vel iudiciorum usus hoc fieri coegerit, vel ipsi magistri legum aliquid ex his perlegere festinabatis, ut sit vobis aliquid amplius discipulorum peritia. Et haec quidem fuerant antiquae eruditionis monumenta, secundum quod et vestro testimonio confirmatur.

La tercera crítica que dirige Justiniano al plan antiguo es la mezcla del ius utile con el ius inutile . Como afirma Archi, «el recurso a la terminología ius utile-ius inutile es muy frecuente en el lenguaje justinianeo. No debe caerse en la tentación de entender el ius utile como el derecho vigente, mientras que el ius inutile como el derecho abolido o derogado. En el lenguaje justinianeo el ius utile, considerado con relación a la enseñanza, no viene determinado por una voluntad legislativa, sino por la necesidad efectiva de la realidad tal y como es históricamente. Respecto a los Digesta, el ius utile es entendido por los justinianeos como todo aquello que sirve para comprender el proceso formativo de la tradición jurídica romana y que no es humanamente posible reducir a preceptos normativos abstractos. Respecto a las Institutiones , el concepto base está constituido por la idea de que es necesario acompañar a la exposición del ius utile de un excursus histórico independiente de toda consideración utilitarista» (I978, I20 y ss.). Para Archi, «Justiniano sabe que él es el único conditor e interprete legum, pero en la realidad histórica en la que opera, no sólo no puede liberarse de la tradición de los iura, sino que reconoce en éstos un patrimonio cultural, a través del cual debe pasar todo estudioso del derecho. Desde este punto de vista, existe una relación de convergencia entre iura y constitutiones; en efecto, el estudio de los iura educa la mente a legere y a suptiliter intellegere las constituciones imperiales, además los primeros constituyen el soporte intelectual y cultural de las segundas» (I978, I28).

\section{El nuevo plan de estudios}

El nuevo plan de estudios que Justiniano diseña y establece en la Constitución Omnem (2-5) tiene una duración de cinco años y un preciso material de estudio, que naturalmente es su reciente Compilación. Después de haber criticado, en los extremos ya analizados, el antiguo plan de estudios, Justiniano nos presenta su nuevo plan en perfecta concordancia con su nueva concepción del Derecho (Omnem, 2 pr.):

Nos vero tantam penuriam legum invenientes, et hoc miserrimum iudicantes legitimos thesauros volentibus aperimus, quibus per vestram prudentiam quodammodo erogatis, ditissimi legum oratores efficiantur discipuli.

La materia viene así distribuida: 
El primer año, los alumnos, que se llamaran en lo sucesivo «jóvenes justinianeos», estudian las Instituciones de Justiniano -elaboradas por Triboniano, Teófilo y Doroteo- que tienen la función de iniciar de una manera breve y sencilla a los alumnos en el aprendizaje del Derecho, es decir, una función propedéutica a los Digesta; al final de su estudio y en el mismo año la primera parte de las leyes, o sea, como se deriva de la lectura combinada de la Const. Tanta, 2, los cuatro primeros libros del Digesto -la parte llamada Prota- que contienen Principios generales sobre el derecho y la jurisdicción: son los libros De Iustitia et Iure, De iurisdictione, De postulando y De in integrum restitutionibus .

El segundo año, los alumnos, que se siguen llamando «edictales», en recuerdo a la obra de Ulpiano, Libri ad Edictum, estudian los siete libros De iudiciis, o bien, los ocho libros De rebus, según lo permita, en cada caso, la duración del curso. Los siete libros del Digesto Sobre los juicios, son los libros 5, 6, 7, 8, 9, го у пг: de iudiciis, de reivindicatione, de usufructus, de servitutibus, de noxalibus actionibus, ad exhibendum, de servo corrupto, que tratan de la doctrina general de las acciones y protección judicial de la propiedad y de los demás derechos reales. Los ocho libros del Digesto Sobre las obligaciones, son los libros I2, I3, I4, I5, I6, I7, I8 y I9: de rebus creditis si certum petetur et de condictione, de condictione furtiva, de lege Rhodia, de peculio, depositi vel contra, mandati vel contra, de contrahenda emptione, locati conducti, que tratan sobre obligaciones y contratos. Estos libros han de estudiarse íntegros y por su orden, sin dejar absolutamente nada de ellos: ... sed eosdem libros de iudiciis vel de rebus totos et per suam consequentiam accipiebant, nullo penitus ex his derelicto... Además estudian cuatro libros más: uno sobre dote -Digesto 23: el primero de los tres dedicados a esta materia; uno, sobre tutela -Digesto 26: el primero de los dos dedicados a esta materia; uno, sobre testamento -Digesto 28: el primero de los dos dedicados a esta materia; y uno sobre legados y fideicomisos -Digesto 30: el primero de los siete dedicados a esta materia. Es la parte que actualmente denominamos Derecho de Familia y Sucesiones. Consta de catorce libros. De los cuales sólo es preceptivo el estudio de los cuatro primeros libros de cada parte: dote, tutela, testamento y legados y fideicomisos, dejando los otros diez para mejor momento, pues ni la duración del curso lo permite ni cabe una explicación detenida de estos catorce libros.

El tercer año, los alumnos se siguen llamando «papinianistas» en honor al gran Papiniano, para quien Justiniano tiene un recuerdo muy emotivo (Omnem, 4):

... Ne autem tertii anni auditores, quos Papinianistas vocant, nomen et festivitatem eius amittere videantur, ipse iterum in tertium annum per bellissimam machinationem introductus est; librum enim hypothecariae ex primordiis plenum eiusdem maximi Papiniani fecimus lectione, ut et nomen ex eo habeant et Papinianistae vocentur, et eius reminiscentes et laetificentur et festum diem, quem, cum primum leges eius accipiebant, celebrare solebant, peragant, et maneat viri sublimissimi praefectorii Papiniani et per hoc in aeternum memoria...

Se completa el estudio De iudiciis o De rebus, en la forma que correspondiese según lo estudiado en el año anterior. Además, estudian tres libros monográficos, tres libri singulares ; son los siguientes: sobre la fórmula hipotecaria -Digesto 20-, sobre el edicto de los ediles y la acción redhibitoria respecto a la compraventa -Digesto, libro 2I, título I- y sobre la evicción y estipulación por el doble y estipulación en garantía por evicción Digesto, libro 2I, título 2-. Se incluye en los estudios de tercer año una selección de textos del Digesto con la doctrina de Papiniano que, según afirma Justiniano, se ofrece al estudio brillando en su tenor auténtico a lo largo de toda la compilación de nuestro Digesto no sólo con sus Respuestas, que se habían redactado en ig libros, sino también con los 37 libros de las Cuestiones, el libro doble de las Definiciones y sobre los adulterios, y con casi toda su obra.

El cuarto año, los alumnos se siguen llamando «resolvedores de casos». Estudian los restantes io libri singulares del Digesto: los libros 24, 25, 27, 29 y del 3I al 36; quedan fuera los libros 26, 28 y 30, que se estudiaron en el año anterior. Es la continuación de la 
parte de Familia y Sucesiones estudiada en el segundo año: donaciones entre cónyuges, testamentos, legados y fideicomisos. Con ello los libros efectivamente leídos de la recopilación de iura se elevaban, en total, a treinta y seis -como había sido anunciado en el pr. de la Const. Omnem-.

Los estudiantes que hasta ahora han tenido al mismo profesor durante los cursos precedentes y para todas las materias, deben cursar un quinto año, quizá sin la obligación de asistir a clases regularmente, los alumnos se llaman «resolvedores avanzados». Estudian los últimos I4 libros del Digesto, esto es, del 37 al 50, a fin de que puedan alegarlos en los juicios los ahora estudiantes. Son los libros que tratan sobre la posesión de los bienes hereditarios, denuncia de obra nueva, manumisiones, interdictos, estipulaciones, delitos, apelaciones, magistrados municipales, etc. Tratan de cuestiones que, en términos muy generales, podrían ser referidas a las ramas del Derecho que hoy denominamos Derecho procesal, Derecho penal o aun Derecho político y administrativo. Además estudian el Código de Justiniano, desde el año 535 en su segunda y definitiva edición, y, las nuevas constituciones justinianeas según se fueron promulgando. Se obtendrá, así, una lectura casi total de las compilaciones justinianeas.

Justiniano, después de presentar su nuevo plan de estudios, expresa su firme convicción de que, con su estudio, los estudiantes no dejarán de conocer nada sobre la ciencia del Derecho, llegando a convertirse en excelentes abogados o en eficaces funcionarios (Omnem, 6):

Discipuli igitur, omnibus iis legitimis arcanis reseratis, nihil habeant absconditum, sed omnibus perlectis, quae nobis per Triboniani, viri excelsi, ministerium ceterorumque composita sunt, et oratores maximi, et iustitiae satellites inveniantur, et iudiciorum optimi tam athletae, quam gubernatores in omni loco aevoque felices.

Como afirman García Garrido y Francisco Eugenio, «verdaderamente, el plan es un plan sistemático, gradual, completo, armónico, de contenido inicialmente más conceptual -como corresponde a los estudiantes que se inician en el Derecho, los estudiantes de los cuatro primeros libros del Digesto, la Prota -y luego, sobre todo al final, esencialmente práctico. Un plan perfectamente programado en cuanto a su contenido. Y explícitamente reglamentado en cuanto al material y método de trabajo: las obras de la compilación -las Instituciones, el Digesto y el Código- que hay que comprender y, en cierto modo, aprender» $(1988,53)$.

Fundamento de tal concepción completa y unitaria del Derecho es la consonantia iuris . Justiniano se propone acabar con toda disputatio , con todo ius incertum, con toda confusio, provocadas por la actividad de los intérpretes y de las mismas escuelas. Lucha Justiniano contra la verbositas de los jurisconsultos que socava la subtilitas legum, la scrupulositas iuris, la subtilitas verborum, la subtilitas dubitatio, la subtilitas divisio; porque precisamente a través de estas subtilitates es como los iuris auctores crean sus disputas infinitas. El Emperador temiendo que se produjese una complejidad e incertidumbre semejante a la que se dio en época postclásica, prohibe rigurosamente en las constituciones de conceptione $\mathrm{y}$ de confirmatione digestorum toda actividad de interpretación o de comentario al texto de su obra (Deo Auctore, i2):

...nullis iuris peritis in posterum audentibus commentarios confundere. Quemadmodum et in antiquioribus temporibus factum est, cum per contrarias, interpretantium sententias totum ius paene conturbatum est.

Y de nuevo (Tanta, 2I):

Alias autem legum interpretationes, immo magis perversiones, eos tractare non concedimus, ne verbositas eorum aliquod legibus nostris afferat ex confusione dedecus; quod et in antiquis edicti perpetui commentatoribus factum est, qui opus moderate confectum huc atque illuc 
in diversas sententias producentes in infinitum detraxerunt, ut paene omnem Romanam sanctionem esse confusam.

Convencido de la bondad de su obra, Justiniano controla también la actividad de los editores en la reproducción y divulgación de los libros de enseñanza, prohibiéndoles cualquier alteración, presente o futura, de sus libros, el derecho oficialmente reconocido, con la aplicación de la pena del crimen falsitatis, más la estimación del doble del valor del libro modificado y su imposibilidad de alegarlo como doctrina en un juicio ${ }^{\mathrm{I}}(\mathrm{Omnem}, 8)$ :

Illud autem, quod iam tum ab initio hoc opus mandantes in nostra Oratione, et post completum in alia nostri numinis Constitutione scripsimus et nunc utiliter ponimus, ut nemo audeat eorum, qui libros conscribunt, signa in his ponere, et per compendium ipsi legum interpretationi vel compositioni maximum afferre dis crimen; scituris omnibus librariis, qui hoc in posterum commiserint, quod post criminalem poenam aestimationem libri in duplum dominio eius, si nescienti dederint, inferre compellentur, cum et ipse, qui talem librum comparaverit, nihil illo eum habebit, nemine iudice ex tali libro fieri recitationem concedente, sed pro non pro scripto eum habere disponente.

Con anterioridad (Deo auctore, $\mathrm{I} 3)$ :

Ne autem per scripturam aliqua fiat in posterum dubitatio, iubemus, non per signorum captiones et compendiosa aenigmata, quae multas per se et per suum vitium antinomias induxerunt, eiusdem codicis textum conscribi, etiamsi numerus librorum significetur, aut aliud quidquidam; nec etenim haec per specialia signa numerorum manifestari, sed per literarum consequentiam explanari concedimus .

Respecto a los estudiantes, además de mantener vigentes las inmunidades otorgadas por los Emperadores precedentes durante el tiempo que permanezcan cursando sus estudios, Justiniano, en la Constitución Omnem (9) impone la prohibición de «ludos exercere» en cuanto que las fiestas estudiantiles daban lugar con bastante frecuencia a verdaderos y propios «crimina», especialmente en las confrontaciones con los estudiantes de primer año. Advierte a los estudiantes que se abstengan de juegos indignos, serviles o injuriosos contra los profesores o sus propios compañeros, bajo la amenaza de severísimas penas:

Illud vero satis necessarium constitutum cum summa interminatione edicimus, ut nemo audeat neque in hac splendidissima civitate, neque in Berytiensium pulcherrimo oppido ex his, qui legitima peragunt studia, indignos et pessimos, imo magis serviles, et quorum effectus iniuria est, ludos exercere, et alia crimina vel in ipsos professores, vel in socios suos et maxime in eos, qui rudes ad recitationem legum perveniunt, perpetrare; quis enim ludos appellet eos, ex quibus crimina oriuntur? Hoc etenim fieri nullo patimur modo, sed optimo ordini in nostris temporibus et hanc partem tradimus, et toti postero transmittimus seculo, cum oportet prius animas, et postea linguas fieri eruditos.

La Constitución Omnem (Iо) indica las autoridades competentes para hacer respetar la prohibición, en Constantinopla al praefectus urbi, y en Berito al Praeses Phoeniciae maritimae, al Obispo y a los profesores de Derecho:

Et haec omnia in hac quidem florentissima civitate vir excelsus, praefectus huius almae urbis, tam observare quam vindicare, pro ut delicti tam iuvenum quam scriptorum qualitas exegerit, curae habebit; in Berytiensium autem civitate tam vir clarissimus, praeses Phoeniciae maritimae, quam beatissimus eiusdem civitatis episcopus, et legum professores.

La Constitución Omnem (Іі) dirige también algunas exhortaciones a los profesores y a los estudiantes -que se deberán de convertir en «optimi iustitiae et rei publicae ministri»-:

\footnotetext{
${ }^{\text {I8 }}$ Sobre el alcance de estas prohibiciones, vid. BERGER (I95I, I58 y sS.).
} 
en lo que quizá puede verse, como por lo demás en otros pasajes de la misma Const. Omnem , una alusión a la doble vertiente profesional del futuro jurista, la forense por un lado y las carreras burocráticas por otro.

Como afirma Bonini, «en la Const. Omnem no se concede relieve, sin embargo, a la mayor dificultad de los estudios, que era la de naturaleza lingüística: la mayor parte de los estudiantes, en efecto, sólo conocía bien el griego, mientras grupos más restringidos, provenientes de las regiones latinas de Oriente, o incluso de Occidente, conocían, sin embargo, sólo el latín, encontrándose, por su parte, con dificultades con las constituciones griegas y en particular con las Novelas. De aquí, y no sólo por las exigencias de los ambientes de la práctica, la necesidad de preparar versiones y comentarios en griego, o viceversa, en latín, de los principales textos jurídicos» (1979, 70).

Tampoco menciona la Const. Omnem cómo han de acreditar los alumnos sus conocimientos jurídicos al terminar sus estudios de Derecho. Cabe pensar que Justiniano mantiene el sistema establecido por León, C. J. 2.7.II.I, y por Anastasio, C. J. 2.7.22(8.3).4 y C. J. 2.7.24(8.5).5, es decir, al terminar los estudios, los alumnos tienen que superar un examen final para obtener el correspondiente diploma o certificado que acredite sus conocimientos jurídicos. Dicha certificación será expedida por el mismo profesor que han tenido los alumnos durante la carrera.

En conjunto, la Const. Omnem parece conducir a una notable racionalización y modernización de los estudios jurídicos y al mismo tiempo, con toda probabilidad, a una acentuada severidad de los mismos ${ }^{19}$. Al cabo de los siglos, ¿̇qué tendremos que aprender de la obra de Justiniano? La conciencia del peligro de la verbositas del jurista y del peligro de la ambiguitas del Derecho. El buen criterio de unos estudios de Derecho orientados a la vida, a la práctica jurídica, y en último término a la justicia, al bien de la República, a la utilidad general ${ }^{20}$.

Afortunadamente el presagio de Spengler en I922 no se ha cumplido cuando acusaba a Justiniano de personaje quijotesco, en cuanto creador de un Código latino condenado a ser simple literatura ${ }^{2 \mathrm{I}}$. En palabras de Iglesias, «no fue un iluso Justiniano. Soñó eternidad para su obra. Y no muerte ha tenido en un curso de largos siglos. Y no muerte, sino vida, en la vida de nuestra Europa, que hizo suyos, en su creación y regimiento, preceptos contenidos en el Corpus iuris , tesoro de sabiduría de siglos» (I978, 227).

\section{Los centros de enseñanza superior}

La Constitución Omnem concluye con una serie de disposiciones más o menos conectadas con la ordenación de los estudios universitarios de Derecho. En particular, Justiniano reduce los centros universitarios públicos autorizados para impartir los estudios jurídicos a Berito, Constantinopla y Roma (Omnem, 7):

Haec autem tria volumina a nobis composita tradi is tam in regiis urbibus quam in Berytiensium pulcherrima civitate, quam et legum nutricem bene quis appellet, tantummodo volumus, quod iam et a retro principibus constitutum est, et non in aliis locis quae a maioribus tale non meruerint privilegium: quia audivimus etiam in Alexandrina splendidissima civitate et in Caesariensium et in aliis quosdam imperitos homines devagare et doctrinam discipulis adulterinam tradere: quos sub hac interminatione ab hoc conamine repellimus, ut, si ausi fuerint

\footnotetext{
I9 BONINI (I979, 70).

${ }^{20}$ GARCÍA GARRIDO y FRANCISCO EUGENIO (I988, 54-55).

${ }^{21}$ ARCHI (1978, I98 y ss.).
} 
in posterum hoc perpetrare et extra urbes regias et Berytiensium metropolim hoc facere, denarum librarum auri poena plectantur et reiiciantur ab ea civitate, in qua non leges docent, sed in leges committunt.

Justiniano ordena que sus tria volumina -Código, Instituciones y Digesto- sean enseñados en las ciudades reales -Roma y Constantinopla- y en la prestigiosa Berito. Añade que existen otros centros de enseñanza del Derecho, pero con un nivel muy inferior, quizá como complemento a los estudios de gramática o de retórica. Centros que no alcanzan el nivel de los modelos anteriormente citados. Triboniano, hablando con un conocimiento personal de estos centros, señala que en Alejandría, Cesarea de Palestina y en otras ciudades existen maestros ignorantes que enseñan una falsa doctrina. Justiniano prohíbe tales centros de enseñanza ${ }^{22}$, conminando a los transgresores con la pena de diez libras de oro y la expulsión de la ciudad donde enseñan ${ }^{23}$.

Esta apuesta de Justiniano por la enseñanza pública viene confirmada por la recepción que llevan a cabo los compiladores de la célebre ley de Teodosio sobre la reestructuración del sistema docente de la Universidad de Constantinopla (C. Th. 14.9.3), la cual tiene para ellos un valor superior al meramente histórico:

C. J. II. I9(I8). I (Impp. Theodosius A. et Valentinianus C. ad P.U.): Universos, qui usurpantes sibi nomina magistrorum in publicis magistrationibus cellulisque, collectos undecumque discipulos circumferre consuerunt, ab ostentatione vulgari praecipimus amoveri, ita ut, si qui eorum post emissos divinae sanctionis adfatus quae prohibemus atque damnamus iterum forte temptaverit, non solum eius quam meretur infamiae notam subeat, verum etiam pellendum se ex ipsa ubi versatur inlicite urbe cognoscat. Illos vero, qui intra plurimorum domus eadem exercere privatim studia consueverunt, si ipsis tantummodo discipulis vacare maluerint, quos intra parietes domesticos docent, nulla huiusmodi interminatione prohibemus, sin autem ex eorum numero fuerint, qui videntur intra. Capitolii auditorium constituti, ii omnibus modis privatarum aedium studia sibi interdicta esse cognoscant scituri, quod si adversum caelestia statuta facientes fuerint deprehensi, nihil penitus ex illis privilegiis consequantur, quae his, qui in Capitolio tantum docere praecepti sunt, merito deferuntur.

La presencia de esta ley en la Compilación revela la intención imperial de monopolizar la enseñanza superior. Al igual que Teodosio, Justiniano quiere distinguir claramente la enseñanza privada de la pública, prohibiendo a los profesores oficiales enseñar privadamente bajo la pena de la pérdida de sus privilegios. Igualmente sanciona a los profesores privados que llevan a cabo una enseñanza pública «no solamente sufra la nota de infamia, sino que sepa también que ha de ser expulsado de la misma ciudad en que ilícitamente ejerce».

\section{La elección de los profesores}

Respecto al sistema de acceso de los profesores de Derecho a la enseñanza oficial, Justiniano mantiene la regulación establecida por Juliano el Apóstata recogida por Teodosio en C. Th. I3.3.5, con la única diferencia de la eliminación del requisito de la ratificación imperial:

${ }^{22}$ Así, KÜBLER (I9I4, 400); COLLINET (I925, 52 y ss.); BARBAGALLO (I9II, 364 SS.); FERRINI (I929, 8); HERNÁNDEZ TEJERO (I972, I63); SÁNCHEZ DEL RÍO (I956, II5); VOLTERRA (I967, 98); SCHULZ (I968, 49I); BONINI (I979, 69). Cfr. COPPOLA (I994, 550 y ss.) ID., afirma «que la citada disposición no excluye la enseñanza privada, ni la enseñanza pública en otras sedes distintas de Roma, Constantinopla y Berito, con una única condición: que en las mismas no se enseñe una falsa doctrina» (I995, 244 y ss.).

${ }^{23}$ Sobre la supresión de la escuela de Atenas, vid. BARBAGALLO, (I9II, 356 y ss.); BUCCI, (I987, 507 y ss.); COPPOLA (I994, 546 nt. 660). 
C. J. IO. 53(52). 7 pr. (Imp. Iulianus A.): Magistros studiorum doctoresque excellere oportet moribus primum, deinde facundia. I. Sed quia singulis civitatibus adesse ipse non possum, iubeo, quisquis docere vult, non repente nec temere prosiliat ad hoc munus, sed iudicio ordinis probatus decretum curialium mereatur, optimorum conspirante consensu .

Por tanto, la disposición transcrita dispone que los docentes de la enseñanza superior -magistri studiorum doctoresque- deben poseer profundos conocimientos de la disciplina que imparten y capacidad para transmitirlos -evidentemente de la Compilación justinianea-y, sobre todo, una moralidad ejemplar. Establece los siguientes requisitos para el acceso de los docentes a la enseñanza pública: I) valoración de los méritos de los candidatos mediante un concurso público denominado probatio, en el que aquellos presentan una muestra de sus conocimientos al juicio unánime de una comisión de notables -optimorum conspirante consensu -, 2) nombramiento, mediante decreto, de la Curia municipal.

Coppola observa que «puede resultar sorprendente que Justiniano, católico por excelencia ${ }^{24}$, haya insertado en su compilación una constitución emanada con fines anticristianos. En su opinión dicha constitución le habría permitido a Justiniano cumplir su política religiosa. En efecto, a través del nombramiento de la Curia se habría elegido a aquellos docentes sobre los que no hubiera duda de su religiosidad» (I994, 543 y ss.).

Justiniano mantiene el mismo número de profesores de Gramática, Retórica, Filosofía y Derecho establecido por Teodosio en su célebre constitución del año 425 por la que reorganiza los estudios superiores de la Universidad de Constantinopla:

C. J. II. I9(I8). I. 2 (Imp. Theodosius A. et Valentinianus C. Constantio P.U.): Habeat igitur auditorium specialiter nostrum in his primum, quos Romanae eloquentiae doctrina commendat, oratores quidem tres numero, decem vero grammaticos: in his etiam, qui facundia Graecitatis pollere noscuntur, quinque numero sint sophistae et grammatici aeque decem. 3. Et quoniam non his artibus tantum adulescentiam gloriosam optamus institui, profundioris quoque scientiae atque doctrinae memoratis magistris sociamus auctores. 4. Unum igitur adiungi ceteris volumus, qui philosophiae arcana rimetur, duo quoque, qui iuris ac legum voluntates pandant, ita ut unicuique loca specialiter deputata adsignari faciat tua sublimitas, ne discipuli sibi invicem possint obstrepere vel magistri, neve linguarum confusio permixta vel vocum aures quorundam aut mentes a studio litterarum avertat .

La constitución anterior es una recepción de C. Th. I4.9.3.I. El claustro de la Universidad de Constantinopla se compone de 3I cátedras, i6 griegas y I5 latinas, repartidas de la siguiente forma: Gramática - diez cátedras griegas y diez latinas-, Retórica -cinco cátedras griegas y tres latinas-, Filosofía - una cátedra griega-, Derecho -dos cátedras latinas ${ }^{25}$. Dichas enseñanzas se imparten en las amplias y decoradas salas dispuestas en forma de hexaedro situadas en la plaza del Capitolio, a fin de que los alumnos y los maestros no se perturben unos a otros y para que la mezcla de lenguas o de voces no aparte del estudio de las letras los oídos o la inteligencia de éstos.

Todos los profesores que imparten su docencia en las universidades estatales tienen derecho a percibir un salario público:

C. J. Iо. 37(36). I (Imp. Constantius A. ad Marcellinum Comitem Orientis): Nulli salarium tribuatur ex viribus rei publicae nisi ei, qui iubentibus nobis specialiter fuerit consecutus.

\footnotetext{
${ }^{24}$ Sobre el catolicismo de Justiniano, vid. BIONDI (I936); BRÉHIER (I946); AMELOTTI (I978, I33 y ss.); SIMONETTI (I985, 9I y ss.); PULIATTI, ( I99I, I6I y ss.; 237 y ss.)

${ }^{25}$ SCHULZ, afirma «que tal vez debieron ser más, pues la Const. Omnem se dirige a ocho profesores» (I968, 492 y nt. 2).
} 
La disposición anterior ${ }^{26}$ sanciona que a nadie y, consiguientemente, tampoco los profesores de Derecho, pueden percibir un salarium con cargo a la res publica a menos que hayan obtenido la correspondiente autorización del Emperador. La citada disposición parece revivir la autorización imperial establecida por Juliano. No obstante, consideramos a la luz de C. J. Io. 53(52). 7 que la disposición imperial hay que interpretarla en el sentido de que hayan superado el sistema de acceso a la enseñanza oficial.

\section{Los privilegios de los profesores}

Justiniano otorga a todos los profesores de artes liberales los mismos privilegios e inmunidades, incluidos los doctores legum, otorgados por sus predecesores. En opinión de Coppola, «los títulos 53(52) y 66(64) del libro décimo del Código justinianeo, intitulados respectivamente de professoribus et medicis $y$ de excusationibus artificium, constituyen la prueba más elocuente de la continuidad entre la política de Teodosio y aquella de Justiniano en lo relativo al trabajo de los intelectuales» (I994, 54I).

Veamos la siguiente constitución:

C. J. Iо. 53(52). 6 pr. (Imp. Constantinus A. ad Volusianum): Medicos, et maxime archiatros vel ex archiatris, grammaticos et professores alios literarum et doctores, una cum uxoribus et filiis, nec non et rebus, quas in civitatibus suis possident, ab omni functione et ab omnibus muneribus civilibus vel publicis immunes esse praecipimus, et neque in provinciis hospites recipere, nec ullo fungi munere, nec ad iudicium deduci, vel exhiberi, vel iniuriam pati, ut, si quis eos vexaverit, poena arbitrio iudicis plectatur. I. Mercedes etiam eorum et salaria reddi iubemus, quo facilius liberalibus studiis et memoratis artibus multos instituant.

La constitución es una síntesis de tres constituciones de Constantino: C. Th. I3.3.I, C. Th. I3.3.2 y C. Th. 13.3.3. En ella Justiniano unifica y confirma los privilegios que ya habían sido concedidos por Constantino a los médicos, médicos y ex médicos de Palacio, gramáticos y profesores de letras, con el único añadido de los doctores legum. Los profesores de estudios liberales, sus esposas, sus hijos y sus bienes, están immunes a todo munus civil o público; a título de ejemplo están exentos de la hospitalitas y de la in ius vocatio . Contra quien incumpla tales disposiciones el juez le impondrá a su arbitrio una pena. Concluye Justiniano con la llamada a los súbditos y a las ciudades para que abonen retribuciones y salarios a los profesores, a fin de que puedan seguir dedicándose a la loable profesión de instruir a la juventud. Obsérvese que en la llamada a los particulares y a las ciudades para el pago de las mercedes y de los salaria a los intelectuales, los Compiladores han seguido la misma motivación que ya se encontraba en C. Th. I3.3.3 y que Constantino había vinculado a la concesión de los beneficia : quo facilius liberalibus studiis et memoratis artibus multos

${ }^{26}$ Esta constitución confirmada por Justiniano procede de C. Th. I2. 2. I: (Imp. Constantius A. ad Marcellinum comitem orientis) (a. 349): Nulli salarium tribuatur ex viribus rei publicae nisi ei, qui iubentibus nobis specialiter fuerit consecutus. Gravitas igitur tua placitis obsequatur.

${ }^{27}$ C. Th. I3.3.I (Imp. Constantinus A. ad Volusianum, a. 32I/4): Medicos, grammaticos et professores alios litterarum immunes esse cum rebus, quas in civitatibus suis possident, praecipimus et honoribus fungi; in ius etiam vocari eos vel pati iniuriam prohibemus, ita ut, si quis eos vexaverit, centum milia nummorum aerario inferat a magistratibus vel quinquennalibus exactus, ne ipsi hanc poenam sustineant, servus eis si iniuriam fecerit, flagellis debeat a suo domino verberari coram eo, cui fecerit iniuriam, vel, si dominus consensit, viginti milia nummorum fisco inferat, servo pro pignore, donec summa haec exsolvitur, retinendo. Mercedes etiam eorum et salaria reddi praecipimus. Quoniam gravissimis dignitatibus vel parentes vel domini vel tutores esse non debent, fungi eos honoribus volentes permittimus, invitos non cogimus; 13.3.2 (Idem A. ad Rufinum P.P., a. 326): Archiatri omnes et ex archiatris ab universis muneribus curialium, senatorum et comitum perfectissimorumque, muneribus et obsequiis, quae administratione perfunctis saepe mandantur, a praestationibus quoque publicis liberi inmunesque permaneant nec ad ullam auri et argenti et equorum praestationem vocentur, quae forte praedictis ordinibus aut dignitatibus adscribuntur. Huius autem indulgentiam sanctionis ad filios quoque eorum statuimus pervenire; 13.3.3 (Idem A. ad Populum a. 333): Beneficia divorum retro principium confirmantes medicos et professores litterarum, uxores etiam et filios eorum ab omni functione et ab omnibus muneribus publicis vacare praecipimus nec ad militiam conprehendi neque hospites recipere nec ullo fungi munere, quo facilius liberalibus studiis et memoratis artibus multos instituant. 
instituant, es decir, la realización de un preciso objetivo didáctico: garantizar la continuidad de una clase intelectual que asegure la transmisión de una verdadera cultura humanística.

En esta línea merece citarse otra constitución en la que Justiniano expresa su elevado concepto sobre los profesores constantinopolitanos hasta el punto de insertarlos en la nobleza imperial:

C. J. I2. I5. I (Imp. Theodosius A. et Valentinianus C. Theophilo P.U.): Grammaticos tam Graecos quam Latinos, sophistas et iuris peritos in hac regia urbe professionem suam exercentes et inter statutos connumeratos, si laudabilem in se probis moribus vitam esse monstraverint, si docendi peritiam facundiamque dicendi interpretandi subtilitatem copiam disserendi se habere patefecerint, et coetu amplissimo iudicante digni fuerint aestimati, cum ad viginti annos observatione iugi ac sedulo docendi labore pervenerint, placuit honorari et his qui sunt ex vicaria dignitate connumerari.

La disposición imperial es una síntesis de otra constitución de Teodosio recogida en C. Th. 6.2I.I, sobre la que Justiniano ha introducido las correspondientes adaptaciones. El Emperador concede a los profesores de gramática, retórica y derecho que ejercen su magisterio en la Universidad de Constantinopla el título de ex vicarios, como reconocimiento a sus veinte años de servicio constante y entrega desinteresada a la enseñanza. Serán acreedores a este título imperial, a juicio de la Curia, aquellos docentes que hayan llevado una existencia loable, moralmente intachable, eficientes en sus enseñanzas, elocuentes en el hablar, sutiles en sus interpretaciones y hábiles en sus disertaciones.

\section{La Pragmatica Sanctio pro petitione Vigilii}

En el año 395 el emperador Teodosio el Grande divide el Imperio entre sus dos hijos: a Arcadio le asigna Oriente y a Honorio, Occidente. Este reparto consuma la división administrativa y política del Imperio. Un aspecto importante de la diferenciación política entre las dos partes imperii residió en la actitud que cada pars adoptó respecto a los bárbaros, ya ampliamente infiltrados en el ejército y la administración pública. Mientras que en Occidente se buscaba convertirlos en inofensivos gracias a una asimilación dosificada, el partido antigermánico prevaleció definitivamente en Oriente. La realización de esta política contradictoria, fuente de enfrentamientos entre los gobiernos de las dos partes del Imperio, desembocó especialmente en el desvío hacia Occidente de los visigodos de Alarico (4OI), que habían entrado primero en el territorio del Imperio de Oriente. La presión ejercida por los visigodos sometió a dura prueba al sistema de defensa de Estilicón, regente del joven Honorio, que se vio constreñido a desplazar sus fuerzas, debilitando así la frontera del Rin. Los suevos, los alanos y los vándalos pudieron así flanquear este río, mientras que los burgundios y los alamanes penetraron por la zona del Meno. El 23 de agosto del 476 las tropas mercenarias bárbaras del ejército Imperial de Italia se rebelaron y nombraron un rey en la persona de Odoacro. A finales del verano, Odoacro depuso al emperador de Occidente, Rómulo Augústulo, cuyas insignias remitió al emperador de Oriente, Zenón. Desde el punto de vista jurídico esto sólo expresaba una nueva reunificación del poder central en manos de Zenón, pero la conciencia del tiempo atribuyó a este acontecimiento una significación más profunda: era la caída del Imperio de Occidente, del auténtico Imperio, del que había sido fundado por Augusto, del único verdadero Imperio romano, y su sustitución por una serie de reinos bárbaros ${ }^{28}$.

\footnotetext{
${ }^{28}$ CANNATA (I996, I04-I05).
} 
El 476 es la fecha de defunción de la Roma histórica, pero no del Derecho romano. En efecto, Italia continuó viviendo con arreglo a las normas tradicionales bajo la dominación ostrogoda y, en particular, a lo largo del extenso reinado de su primer rey, el gran Teodorico $(493-526)^{29}$, merced al concurso de aquellos dos insignes intelectuales que se llamaron Boecio y Casiodoro.

Teodorico siguió el camino ya recorrido por los Emperadores romanos, manteniendo el desarrollo de los estudios y las cátedras estatales de Gramática, Retórica, Jurisprudencia y Medicina, que atraían a Roma a los estudiantes de las más lejanas provincias, según aparece en un parágrafo de la Pragmatica Sanctio pro petitione Vigilii ${ }^{30}$, ley editada por Justiniano el I3 de agosto del año 554, a finales de la guerra greco-gótica, a una petición del Papa Vigilio, para poner fin a la situación creada en Italia tras su reconquista bizantina. Justiniano ordena que se paguen los salarios a los profesores públicos en la cantidad necesaria para que puedan seguir instruyendo a las nuevas generaciones de estudiantes:

App. VII, c. 22: Ut annona ministretur medicis et diversis. Annonam etiam, quam et Theodoricus dare solitus erat et nos etiam Romanis indulsimus, in posterum etiam dari praecipimus, sicut etiam annonas, quae grammaticis ac oratoribus vel etiam medicis vel iurisperitis antea dari solitum erat, et in posterum suam professionem scilicet exercentibus erogari praecipimus, quatenus iuvenes liberalibus studiis eruditi per nostram rempublicam floreant.

Como afirma Coppola, «este capítulo 22 del Apéndice representa una prueba de la observancia por parte de Teodorico de las disposiciones legislativas precedentes existentes en esta materia. Significativa en tal sentido es la expresión dare solitus erat que pone de relieve el respeto y continuidad del Soberano a las normas preexistentes» (I994, 364 y ss.). Por otra parte, Archi «ha destacado la frase final: quatenus iuvenes liberalibus studiis eruditi per nostram rempublicam floreant, con la que Justiniano declara la necesidad de tener una clase dirigente culta, no con fines ornamentales sino para salvaguarda de la respublica. En otras palabras, la asignación de salarios públicos está condicionada al hecho de que difundan sus conocimientos entre los jóvenes» (I98I, 2009).

La política de Teodorico sobre la concesión de annonae a los profesores de Derecho es continuada por Atalarico. Según nos informa Casiodoro ${ }^{3 \mathrm{I}}$, Atalarico trata de

${ }^{29}$ Sobre la política legislativa de Teodorico en Italia, CALASSO (Milano I954, 74 y ss.). Sobre el Edictum de Teodorico y los problemas que ha suscitado, vid. entre otros, RASI, (I953, I05 y ss.); ID. ( I956, 349 y ss.); ID. (I96I/62, II3 y ss.); PARADISI, (I965, I y ss.); ASTUTI, (I97I, 647 y ss.); ID., (I984, 4I y ss.); VISMARA (I956, 49 y ss.); ID., (I970, 4I8 y ss.); ID. (I987, I y ss.); LAMBERTINI ( I99I, I7 y ss.); CANNATA, (I996, II7 nt. 77).

30 Vid. ARCHI (I98I, I97I y ss.); HÄRTEL, (I976, 33 y ss.).

${ }^{31}$ Cas., var. 9.2I: ... Nuper siquidem, ut est de vobis cura nostra sollicita, quorundam susurratione cognovimus doctores eloquentiae Romanae laboris sui constituta praemia non habere et aliquorum nundinatione fieri, ut scholarum magistris deputata summa videatur imminui. Quapropter, cum manifestum sit praemium artes nutrire, nefas iudicavimus doctoribus adulescentium aliquid subtrahi, qui sunt potius ad gloriosa studia per commodorum augmenta provocandi.... Qua de re, patres conscripti, hanc vobis curam, hanc auctoritatem propitia divinitate largimur, ut successor scholae liberalium litterarum tam grammaticus quam orator nec non et iuris expositor commoda sui decessoris ab eis quorum interest sine aliqua imminutione percipiat et semel primi ordinis vestri ac reliqui senatus amplissimi auctoritate firmatus, donec suscepti operis idoneus reperitur, neque de trensferendis neque de imminuendis annonis a quolibet patiatur improbam quaestionem, sed vobis ordinantibus atque custodientibus emolumentorum suorum securitate potiatur, praefecto urbis nihilominus constituta servante. Et ne aliquid pro voluntate praebentium relinquatur incertum, mox ut sex menses exempti fuerint, statutae summae consequantur praedicti magistri mediam portionem, residua vero anni tempora cum annonarum debita redhibitione claudantur: ne cogantur de alieno pendere fastidio, cui piaculum est vel horarum aliquo vacasse momento. In tantum enim quae sunt decreta volumus firmissime custodiri, ut si quis cuius interest differendam putaverit hanc quasi debitam functionem, procurato more usurarum dispendia ipse patiatur, qui iusta commoda laudabiliter laborantibus plectenda cupiditate subtraxit.... Hoc autem praesentibus litterarum magistris venerando coetui vestro praecipimus intimari, ut sicut nos agnoscunt de suis commodis esse sollicitos, ita a se provectus adulescentium enixius noverint [nos] exigendos... Ecce iam habere tolerabile probantur hospitium: unde nunc merito, uni sollicitudini iugiter inhaerentes, toto vigore animi ad bonarum artium studia transferantur. 
poner fin a la incertidumbre de los docentes públicos sobre el cobro de sus salarios estableciendo que el pago se realice semestralmente, en su caso con intereses, y encarga su cumplimiento al Senado de Roma, quien además debe ratificar los nombramientos de los aludidos docentes. El encargado de ejecutar las decisiones de la Asamblea senatorial sería el prefecto de la ciudad.

La Pragmatica Sanctio posee otra vertiente relevante, extender a Italia la legislación de Justiniano. La compilación justinianea estaba, teóricamente, preparada para tener igual vigencia en todas las partes del Imperio y, por tanto, también en Italia:

App. VII, c. II: Ut leges imperatorum per provincias eorum dilatentur. Ius insuper vel leges codicibus nostris insertas, quas iam sub edictali programmate in Italiam dudum misimus, obtinere sancimus. Sed et eas, quas postea promulgavimus constitutiones, iubemus sub edictali propositione vulgari, (et) ex eo tempore, quo sub edictali programmate vulgatae fuerint, etiam per partes Italiae obtinere, ut una Deo volente facta republica legum etiam nostrarum ubique prolatetur auctoritas .

Como afirma Cannata, «este pasaje contiene el enunciado menos retórico, más sencillo y conciso del programa de Justiniano para restablecer la unidad -de hecho y de derecho- del Imperio romano. El texto nos informa también con precisión sobre el envío de copias del Digesto, de las Instituciones y del Código a Italia; fue por medio de esta misma Pragmatica Sanctio que las tres colecciones fueron promulgadas para Italia y la ley añadía que se haría lo mismo para las constituciones posteriores al Código del 534, es decir, para las Novelas de Justiniano. Dichas Novelas eran normalmente redactadas en griego; sólo a veces eran bilingües, a saber, en latín. No disponemos de información sobre su transmisión oficial en Occidente, pero existen colecciones no oficiales que seguramente fueron redactadas para su utilización en los territorios de lengua latina. Un epitome Iuliani quizá fue ocasionada justamente por la Pragmatica Sanctio pro petitione Vigilii» (1996, I26).

\section{Bibliografía}

AMELOTTI (I978): Giustiniano tra teologia e diritto, L'Imperatore Giustiniano, storia e mito, Milano.

- (I983): Appunti su Giustiniano e la sua compilazione, Torino.

ARCHI (I978): Giustiniano e l'insegnamento del diritto, L'Imperatore Giustiniano, storia e mito, Milano.

- (I98I): Pragmatica sanctio pro petitione Vigilii, Scritti di Diritto romano, vol. III, Milano.

- (I995): Le Institutiones di Giustiniano e l'unità del Corpus Iuris, Scritti di Diritto romano, vol. IV, Milano.

ASTUTI (I97I): Note sull'origine e attribuzione dell'«Edictum Theodorici Regis», Studi Volterra, vol. V, Milano.

- (I984): Tradizione romanistica e civiltà giuridica europea, vol. I, Napoli.

BARBAGALLO (I9II): Lo Stato e l'istruzione pubblica nell'Impero romano, Catania.

BERGER (I95I): The Emperor Justinian's Ban upon Commentaries to the Digest, Bolletino dell'Istituto di diritto romano, $\mathrm{n}^{\circ} 55-56$, Milano.

BIONDI (I936): Giustiniano primo principe e legislatore católico, Milano.

BONINI (I979): Introducción al estudio de la edad justinianea, trad. esp. de Álvarez de Cienfuegos, Granada.

BRÉHIER (I946): La politique religieuse de Justinian, en Histoire de l'Eglise, $n^{\circ}$ 4, Paris.

BUCCI (I987): La politica culturale di Cosroe Anusirvan (53I-579). La chiusura delle scuole di Atene (529) e l'esilio degli ultimi maestri pagani in Persia, Studi Biscardi, vol. VI, Milano.

CALASSO (I954): Medio evo del diritto. Le fonti, Milano.

CANNATA (I996): Historia de la ciencia jurídica europea, trad., esp. de Gutiérrez Masson, Madrid.

COLLINET(I925): Histoire de l'Ecole de droit de Beyrouth, Paris.

COPPOLA (I994): Cultura e potere. Il lavoro intellettuale nel mondo romano, Milano.

- (I995): Giustiniano e I «doctores legum», Labeo. Rassegna di diritto romano, nº 4I, Napoli. 
DANNENBRING (1972): Arma et iura: Ueber die justinianische Gesetzgebung im Rahmen ihrer eigenen Zeit, Acta Classica, I5.

DE FRANCISCI (I954): Síntesis histórica del Derecho romano, trad. esp. Álvarez Suárez, Madrid.

FERNÁNDEZ BARREIRO (I998): El factor jurisprudencial como elemento de identidad de la cultura jurídica europea, Granada.

FERNÁNDEZ DE BUJÁN, A. (20I0): Derecho Público Romano, Madrid.

FERRINI (I929): Le scuole di diritto in Roma antica, Opere di Contardo Ferrini, vol. II, Milano.

GARCÍA GARRIDO y FRANCISCO EUGENIO (I988): Estudios de Derecho y Formación del Jurista, Madrid.

HÄRTEL (I976): Zur Problematik der pragmatischen Sanktionem, spez. zur Sanctio pragmatica pro petitione Vigilii, IURA. Rivista internazionale di diritto romano e antico, $\mathrm{n}^{\circ} 27$, Napoli.

HERNÁNDEZ TEJERO (I972): La Constitución Imperatoriam Maiestatem, Revista de la Facultad de Derecho de la Universidad de Madrid, vol. I6, $\mathrm{n}^{\mathrm{a}}$ 43, Madrid.

IGLESIAS (I978): Derecho romano, «Iuvenes» y «Antecessores», en Estudios Jurídicos en homenaje al Prof. Ursicino Álvarez, Madrid.

KÜBLER (I9I4): s.v. Rechtsunterricht, Pauly-Wissowa, Realenzyklopädie der klassischen Altertumswissenschaft,I A I, Stuttgart.

LAMBERTINI (I99I): La codificazione di Alarico II, Torino.

NARDI (I973): Istituzioni di diritto romano, 3 vols., Milano.

PARADISI (i965): Critica e mito dell'editto teodoriciano, Bulletino dell'Istituto di diritto romano, $\mathrm{n}^{\circ}$ 68, Milano.

PULIATTI (I99I): Ricerche sulle novelle di Giustino II. La legislazione imperiale da Giustiniano I a Giustino II, 2, Problemi di diritto privato e di legislazione e politica religiosa, Milano.

RASI (I953): Sulla paternità del c. d. Edictum Theodorici Regis, Archivio giuridico Filippo Serafín, $\mathrm{n}^{\circ}$ I45, Módena.

- (1956): La legislazione giustinianea e il c. d. Edictum Theodorici, Studi De Francisci, vol. IV, Milano.

- (I96I-62): Ancora sulla paternità del c. d. Edictum Theodorici, Annali di storia del diritto n ${ }^{\circ}$ 5/6.

SÁNCHEZ DEL RÍO (I956): Apuntes para un intento de interpretación sociológica de la enseñanza del Derecho romano, en Revista de Educación, $\mathrm{n}^{\circ} 40$.

SCHELTEMA (I970): L'enseignement de droit des antecesseurs, Leiden.

SCHULZ (I968): Storia della Giurisprudenza romana, trad. ital. Nocera, Firenze.

SIMONETTI (I985): La politica religiosa di Giustiniano, Il mondo del diritto nell'epoca giustinianea. Caratteri e problematiche, Ravenna.

SINAÏSKI (I935): Ordre des matières dans la législation de Justinien, Studi in memoria di Albertoni, vol. I-I, Padova.

VISMARA (I956): El Edictum Theodorici, Estudios Visigóticos, vol. I, Roma-Madrid.

- (I970): Una pretesa nuova testimonianza intorno all'«Edictum Theodorici», Studia et Documenta Historiae Iuris, $\mathrm{n}^{\circ} 36$, Roma.

- (I987): Edictum Theodorici, Scritti di storia giuridica, vol. I, Milano.

VOLTERRA (I967): Giustiniano I e le scuole di diritto, Gregorianum, n 48.

\section{Abreviaturas}

\section{FUENTES}

C. Th. Codex Theodosiani

C. J.- Codex Iustiniani

App.- Apéndice de la Pragmatica Sanctio pro petitione Vigilii. 